\title{
Uncovering the Knowledge Flows in Supply Chain Relationships
}

\author{
Diego Jacob Kurtz ${ }^{1,2}$, Jane Lucia S. Santos ${ }^{1,2,3}$, Gregorio Varvakis ${ }^{1,2}$ \\ ${ }^{1}$ Department of Knowledge Engineering, Federal University of Santa Catarina (UFSC), Florianopolis, Brazil; ${ }^{2}$ Sustainability Man- \\ agement Research Group, Federal University of Santa Catarina (UFSC), Florianopolis, Brazil; ${ }^{3}$ Interdisciplinary Research Group on \\ Knowledge, Learning and Organizational Memory, Federal University of Santa Catarina (UFSC), Florianópolis, Brazil. \\ Email: diegokurtz@gmail.com, jane@egc.ufsc.br, grego@egc.ufsc.br
}

Received September $11^{\text {th }}, 2012$; revised October $11^{\text {th }}, 2012$; accepted November $2^{\text {nd }}, 2012$

\begin{abstract}
The acquisition process of knowledge by organizations is not easy and its spread among individuals, organizations and networks is even more complex. The understanding of the mechanisms involved in the knowledge flow between organizations can help to minimize the problems associated with processes in supply chains. In this paper, we present a systematic search of literature, which aimed to identify the relevance of this issue and how it has been studied on the academic literature. We performed an identification and mapping of knowledge flows between two types of organizations (inter-firm level) of Brazilian chain pig farming: industries and producers (farmers). Among the agricultural activities, this activity is one of the most aggressive to the environment. Some factors associated with environmental sustainability and current market barriers in this chain were identified, where it is necessary to consider the dynamics of knowledge flows. For knowledge flows and practices being effectively implemented across organizations, it was noted that issues such as the motivation of the members are key factors which in order to apply valuable knowledge. Considering this, it is necessary that the reasons and benefits for sharing being clearly established. This study contributes to the perception of the importance of identify and map knowledge flows. It also contributes to the realization of further empirical research in order to examine knowledge flows among organizations.
\end{abstract}

Keywords: Knowledge Flow; Environmental Sustainability; Supply Chain; Knowledge Management

\section{Introduction}

Knowledge has become the most valuable resource of organizations, which is considered as the main source of competitive advantage [1,2]. Knowledge management can be seen as a means to increase the competitiveness of organizations through the creation, dissemination, sharing and use of knowledge [3].

Considering the knowledge management is essential for the competitiveness and sustainability of organizations, the challenge is to develop mechanisms that enable the creation, dissemination and use of knowledge. However, the creation and/or acquisition of knowledge by organizations is not easy [4] and its dissemination between individuals, organizations and networks is even more complex [5-7].

It's possible to identify at least two patterns of organizational knowledge dissemination. The first refers that knowledge flows are geographically located [8] and the other one assumes that knowledge is diffused more easily within than among organizations [7,9].
Knowledge can be extremely difficult to be transmitted across regional boundaries (geographical) in some cases, but, in the other hand could be relatively close among organizations [4]. In this way, to understand the knowledge flow in a supply chain can facilitate the creation, modification, dissemination, and application of knowledge in this context. This is evident in processes related to the dissemination of knowledge, which can be understood by modeling the knowledge flow between the organizations involved.

It is important to consider that the knowledge flow exists at individual, group and organizational levels. The mechanisms involved in the flow between organizations can help to improve solutions and minimize problems associated with processes within supply chains.

This paper presents some ways to analyze knowledge flows between organizations. A literature review was conducted discussing the main issues addressed in the research up until 2010. Finally, we illustrated how the theory of these cases and analogies can be applied in a production chain to reduce bottlenecks and problems. 


\section{Theoretical Background}

\subsection{Knowledge Flow}

Knowledge flow is defined as the process of knowledge "movement" from a source to a receptor and its subsequent absorption and utilization, in order to improve the organization's ability to perform the activities [3]. This can be understood as a process of knowledge passing between people or knowledge processing mechanisms [10].

According to Zhuge [3], the points of issuing/the receiver of knowledge is known as a "knowledge node". The flow has three key attributes: direction, content and a carrier, which respectively determine who sends and who receives, the knowledge content, and the way in which the content is transmitted. A knowledge node can be "a team member" a "role", or a knowledge portal or process [10].

Yoo, Suh and Kim [11], pointed out that knowledge flow in organizations can identify problems in the corresponding business processes. Clear identification and optimization of the knowledge flow can ensure the effective use of knowledge within the organization, enhancing the dynamic between organizational knowledge and business processes.

Mapping and identifying the knowledge flow are strategically important to organizations in three main aspects [11]:

1) The flow of knowledge transmits the know-how generated in a sub unit to other locations within the organization;

2) Knowledge flows facilitate the coordination of workflows linking several sub units which are geographically dispersed;

3) Knowledge flows enable organizations to capitalize business opportunities that require collaboration of several subunits.

The advantages and importance of organizations to understand how knowledge flows within their structures is clear. It becomes crucial in understanding the characteristics of these flows and their representative forms.

\subsection{Knowledge Flow Characteristics}

The fundamental characteristics that constitute a knowledge flow are [3]:

1) Accumulation of information: enables the accumulation of information and or knowledge during task execution. It also allows to keep the knowledge for later use;

2) Classification: ability to classify knowledge according to different projects and different work teams;

3) Abstraction: the ability to reflect about the knowledge at different levels of abstraction and refine its content;
4) Analogy: should establish similar associations between related content;

5) Management of the version: shall support the management of the evolutionary process of knowledge flow through addition, union and/or disposal of the flows.

Zhuge [3] indicates four basic types of knowledge flow (Figure 1):

1) Sequence Connection: knowledge comes from two streams and forms one unique stream;

2) Junction connection: two or more streams converging in one flow only;

3) Division of flows: the flow can be divided into two or more flows of knowledge;

4) Dissemination of the flows: the flow can be distributed into multiple streams of knowledge.

Yoo, Suh and Kim [11] proposed ten guidelines in order to diagnose and redesign the flow of knowledge processes. These guidelines aim to organize the flow of knowledge maps, aligning it with the processes of an existing workflow. According to this set of guidelines, is argued that the knowledge flow must be linear, clear and objective, avoiding parallel flows of knowledge (unnecessary flows) within the same check point and/or business process. Moreover, it is important to consider the objectives of these businesses and for its sub-processes and tasks.

The model proposed by [11] aims to redesign business processes by mapping the knowledge flow. According to the authors, we can infer that the redesign of processes based on knowledge flow reduces costs and time need for tasks, maintain the quality standard and makes business processes more flexible.

Zhuge [3] and Yoo, Suh and Kim [11] did some works on knowledge flows from business processes within organizations. However, the findings at the moment are not enough about how the knowledge flows can be identified and mapped in the inter-firms relationship context.

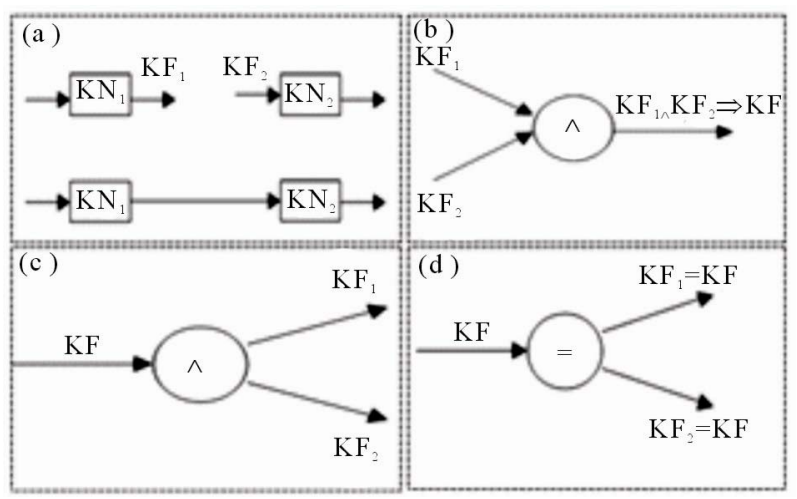

Figure 1. Representation of the knowledge flows. Source: Adapted from Zhuge [3]; "KN: Knowledge; Node/KF: Knowledge Flow. 


\section{Research Process}

This study was conducted in two research phases: 1) Searching the literature; 2) Mapping inter-firms knowledge flows, as described below.

\subsection{Phase 1: Searching the Literature}

The first phase of the research was a systematic search of literature, according to the following steps: a) identification of the subject of the study (by selecting and setting the keywords and search terms); b) identification and selection of database; c) search in the database according the criteria for selection of publications; and d) analysis of the publications in the area, in order to identify research knowledge gaps. Next, the steps will be presented in a detailed way.

1) The first step was an identification of the subject of this study (by setting the keywords and search criteria). As a result of the findings, it was identified that the issue "knowledge flow" has been associated with knowledge management. In order to maximize the possibility of including the full range of relevant publications on the subject, we used this keyword and its derivatives.

2) The second step was composed by the identification and the choice of a data base. We chose the Scopus database because of its academic recognition of being one of the largest databases of abstracts and citations of peerreviewed scientific literature, which includes smart tools to track, analyze and visualize scientific production [12].

3) After that, we did a literature search in the database. We looked for "knowledge flow" in the fields "titles, abstracts, and keywords" publications. We considered the period of September of 2010 until the oldest available database search: which was in 1960.

The criteria used was those inserted in the fields "article" or "review" or "article in press" indexed in the "areas" "Business, Management and Accounting" and "Computer Science". The result of this search was a sample of 341 publications.

4) The last step of the first phase was organized by doing the profile analysis of published data. The 341 papers were used as the basis for performing the following analyses: number of articles published per year, the most relevant papers on the knowledge flow field (identified from the number of citations) and the main theoretical approaches of these works and gaps for the research. These analyzes will be presented in the results section of this paper.

\subsection{Phase 2: Mapping Inter-Firms Knowledge Flows}

The illustration of flows was based on the model proposed by Zhuge [3]. The processes mapped were ob- tained through a review of studies concerning the swine production chain in Brazil $[13,14]$. This supply chain was chosen because it contained some problems related to environmental aspects (could be reflected in the market performance). We believe that a full understanding of knowledge flows will assist in tackling and dealing with the gaps and achieve new potential markets that are currently blocked due to current problems.

\section{Results}

\subsection{Profile of the Literature on Knowledge Flows}

Previous studies have summarize the literature from different fields and have pointed a growing interest in issues related to Knowledge Management, such as intellectual capital [15], organizational memory [16], among others. We have identified that the publications on knowledge flow is also growing (Figure 2). Similar to what happens in other fields of research (e.g., organizational memory), studies on knowledge flows began with a technological approach focused on the organizational level of analysis. The emphasis of these studies is usually in the application of IT and knowledge engineering (e.g. knowledgebased systems, expert systems) to support knowledge flows within organizations.

It was observed that the term "knowledge flow" appears in the research for the first time in 1990, in a paper entitled "Toward Implementation of successful knowledge-based systems: expert systems versus knowledge sharing systems" of Kiyoshi Niwa. The paper points out the crucial role of the knowledge flow (from the knowledge suppliers through knowledge-based systems-KBS).

In order to understand the approaches of these studies about knowledge flows, we identified the twenty most relevant papers from the number of citations in the Scopus database. These 20 documents were included in our high impact papers group.

Figure 3 shows the bibliometric representation of

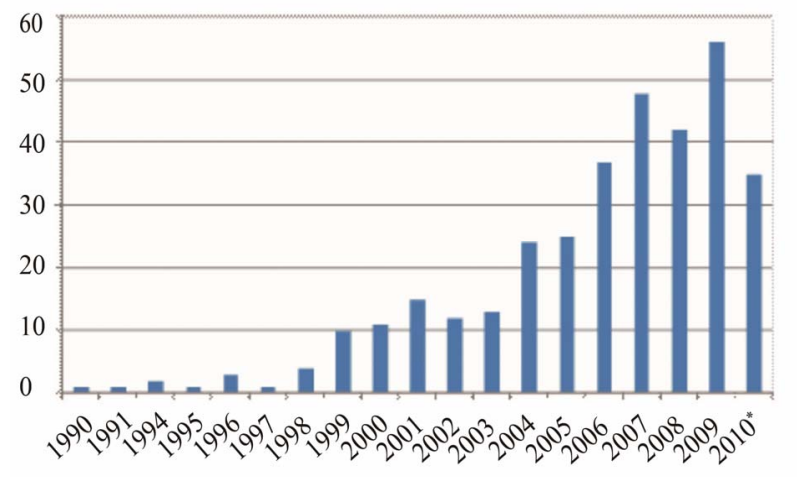

Figure 2. Number of publications on knowledge flow per year. Source: Scopus database; "Results until September 2010. 
these papers (The "total number of citations" refers to the records of accumulated citations available from the base Scopus in September 2010).

In these studies, different approaches are observed. Some of these works deal with concepts of knowledge flows within organizations (organizational level), specifically within multinational organizations which are geographically distributed in subunits [5,17-19].

Other studies seek to investigate the relationship between stocks and flows of organizational knowledge and organizational performance [20], and how learning affects organizational subunits in the flow of knowledge among subunits [21]. However, the predominant level of organizational analysis is clear.

There are few studies on the knowledge flows in the context of networks and inter-firm relations [6,22].

Dyer and Nobeoka [22] pointed out the importance of looking at the knowledge flow through a network of inter firm routines, suggesting that the ability of learning that creates competitive advantage should be extended beyond organizational boundaries.

The discussions of current literature follow the trends showed in our systematic search. This is noticeable, for example, in study of [23] that indicates the flows and the effective sharing of organizational knowledge as particu- larly relevant for multinational corporations. Especially where firm-specific tacit knowledge (know-how) is considered a source of competitive advantage for subsidiaryies participating in a global strategy.

Another recent work pointed that the inter units knowledge flows provide opportunities for mutual learning, favour the running of local and global operations, and foster innovation processes. Tagliaventi, Bertolotti and Macrì [24], for example, showed that what triggers systematic knowledge flows across business units is mainly the sharing of the same professional values and identity, which are indispensable to create trust and foster cooperation.

Our systematic search of literature pointed to several studies and reviews (past and present) on knowledge flows. However, only the model proposed by Zhuge [3] suggests ways to identify and map knowledge flows. Focusing at the same level of the organizational analysis, it appears that this approach can be applied in an inter level context.

In sum, it was found that our research identified a lack of studies that show operationally how to map knowledge flows (only in [3]), especially in inter-firm relationships (none of the studies identified the context of a production chain, for example). This paper contributes to

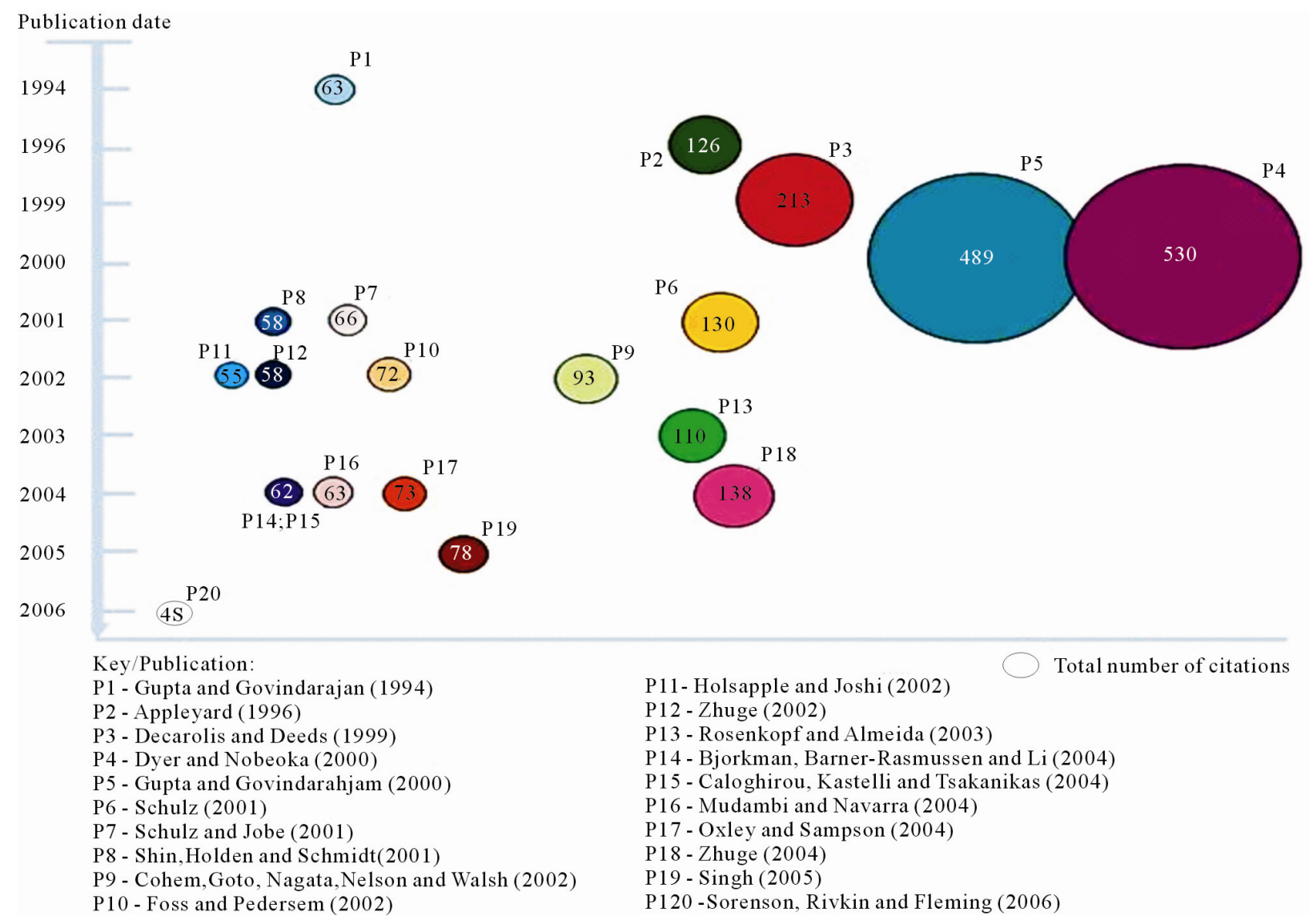

Figure 3. Bibliometric representation of the high impact papers on knowledge flow. 
reduce these research gaps. In the following section we discuss aspects related to the identification of knowledge flow among organizations using examples of the Brazilian swine chain.

\subsection{Mapping Inter-Firms Knowledge Flows in Supply Chain}

Among the 16 largest companies in the segment of swine meat in the world, four are Brazilian [25].

The development of the activity in recent years has resulted in specialization and productive transformation of the sector. The internal and external standards, since the production process until is commercialization, involve the supply of genetic material, feed and controlling of management practices to ensure a strict schedule of production [26].

The scope of this study, considers the productive segment in which inserted industries and the integrated producers represent $88 \%$ of the technical establishments in Brazil [27].

A good information flow is essential for uniformity and efficiency in these systems. In Europe, especially Denmark and Holland, models of integrated quality management in the production chain were successfully implanted [28].

In the recent years there has been an intensification of production (more animals per unit into a smaller number of properties). This situation has increased the existing environmental problems, creating a greater demand for alternatives and processes that reduce or even eliminate the generation of waste in this segment of the chain [13, 25].

The environmental impacts and the inadequate management of resources are damaging the business (through fines, limiting access to credit lines and commercialization barriers) and creating barriers to the importation of Brazilian swine meat (USA; EU countries and Asia) due to the threat of Foot and Mouth Disease (FMD). Weydmann [13] discusses that the current barriers related to animal sanity may also be added to future environmental barriers, in case exporting countries which already have regularized their production chain (USA) - and consequently have higher production costs-decide to claim the environmental dumping for countries that pre- sent some kind of inadequacy of production systems.

In order to achieve homogeneously of production and implement practices to decrease the impact caused by production process, the industry invests in Research \& Development (e.g. management practices, animal diets, genetics and medicines) and procedures based on environmental legislation which are often poorly designed, with applications which are often inadequate to the region's reality, or are not supervised by the government
$[13,26,27]$. It is the responsibility of the producer, the application of the practices and the instructions transmitted by industry. Factors such as motivation, understanding and perception of the value about the practices transmitted should be clear, otherwise practices will not be implemented.

Explicit knowledge (about production standards, for example) can be easily coded and transferred to a large group (e.g., through meetings between industries and farmers-suppliers). On the other hand, tacit knowledge (about how to do a practice, for example) requires intense interaction and frequently these knowledge flows are successful only in a small group and in a specific location where knowledge is used. The more intensive and often meetings with groups occur, the greater the possibly of sharing tacit knowledge along the knowledge flow will be. The organizations need to develop multilateral ways to easily share knowledge between them.

In this sense, the dynamics of knowledge flows among organizations are more complex than within organizations because it involves critical aspects related to motivation, costs (financial and nonfinancial) and distribution of benefits among organizations. In this way, the knowledge that flows between organizations is necessary to motivate its members to share knowledge considered valuable. To achieve this, it is necessary that the reasons and benefits of sharing are clearly established.

In the relationships among organizations it is common to notice cases in which the benefits only exist in a single-direction, where organizations just enjoy the benefits of the collective (e.g. knowledge), without contributing to its creation and/or maintenance. In addition, there are several costs to locate and access the different types of knowledge. These costs could be linked to inefficiencies in the knowledge sharing process, when the paths to facilitate knowledge flows between members are not created [22].

Figure 4 shows how knowledge can flow between the farmers and industries within the segment studied. Industry transmits knowledge (operating procedures) to the farmers, which is fed back to them (industries) through questions related to their acceptance, adaptation, viability and motivation to use the knowledge provided. From this response, Industry can implement and standardize improvements to the processes involved.

The achievement or not of certain management practices recommended by industries (input) can result (processing) at different levels of aggression (output) to the environment in which the swine producers are inserted. The pattern of knowledge dissemination (Figure 5) facilitates the operation of processes such as traceability of the animals, formulations of new products for creation, implementation of software and management of the residues. 


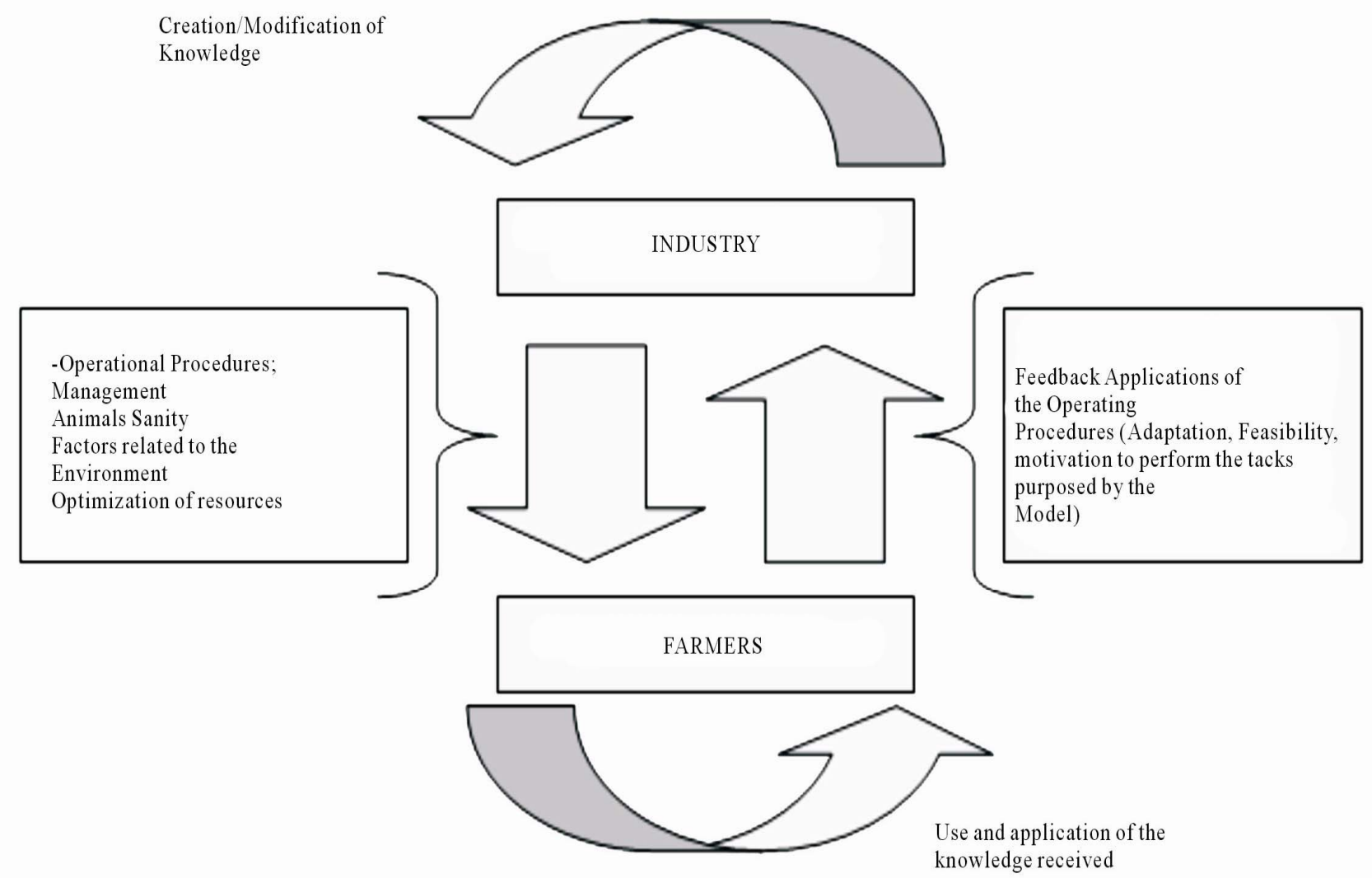

Figure 4. Representation of the knowledge cycle that flows between the industry and farmers.

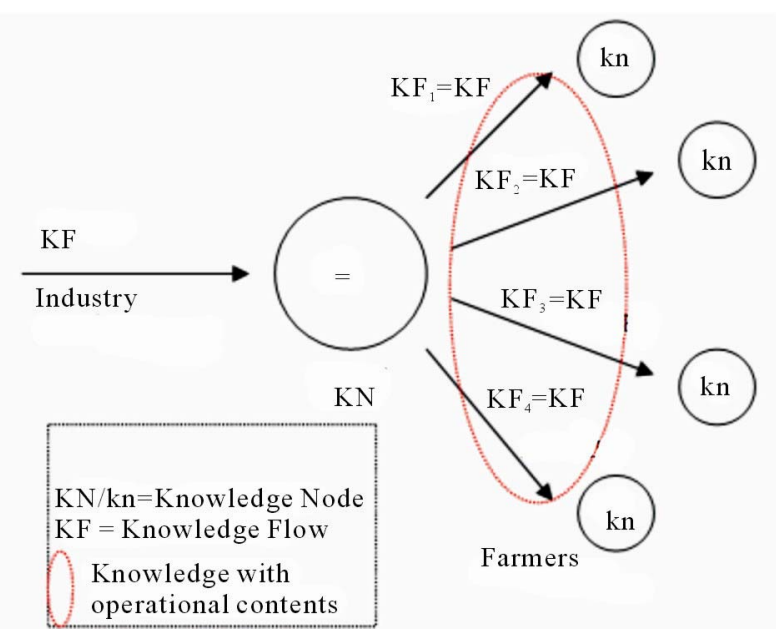

Figure 5. Knowledge dissemination from industries to farmers.

In the relationship between the Industries and the pig farmers, identifying the knowledge flow contained in the workflow (business processes) may indicate possible existing gaps related to environmental problems, production and/or business that could be noticed in this segment of the chain.

The practices carried out by the farmers $(\mathrm{kn})$ came from the knowledge diffused by Industry $(\mathrm{KN})$, and its use, application and motivation for the execution of tasks are directly related to issues such as content (knowledge that is being transmitted) and the form (tacit-through meetings, visits to the property, or explicit-through operation manuals).

The use of the knowledge diffused by the industries $(\mathrm{KN})$ generates a feedback, from the farmers $(\mathrm{kn})$ to the industries (KN) (Figure 6). This response can be positive, with the acceptance, implementation and an appropriate operation of the practices carried out from the knowledge provided. Process improvements can also arise from everyday experiences of the farmers and can be used to create new knowledge that can be transmitted from industries to the entire segment. On the other hand, feedback can be negative in situations where knowledge diffused from industries to the farmers is not seen as positive and without benefits after implementation. This can happen due to infeasibility (technical or financial) or a lack of motivation to carry out the proposals (lack of education, inadequate dissemination of knowledge).

It is essential that the diffusion of knowledge (environmental education/technical and financial support) occurs in a clear and homogeneous way for all the farmers in order to achieve standardization of production processes. In other words, the acceptance and a successful diffusion of knowledge and practices by all members of 


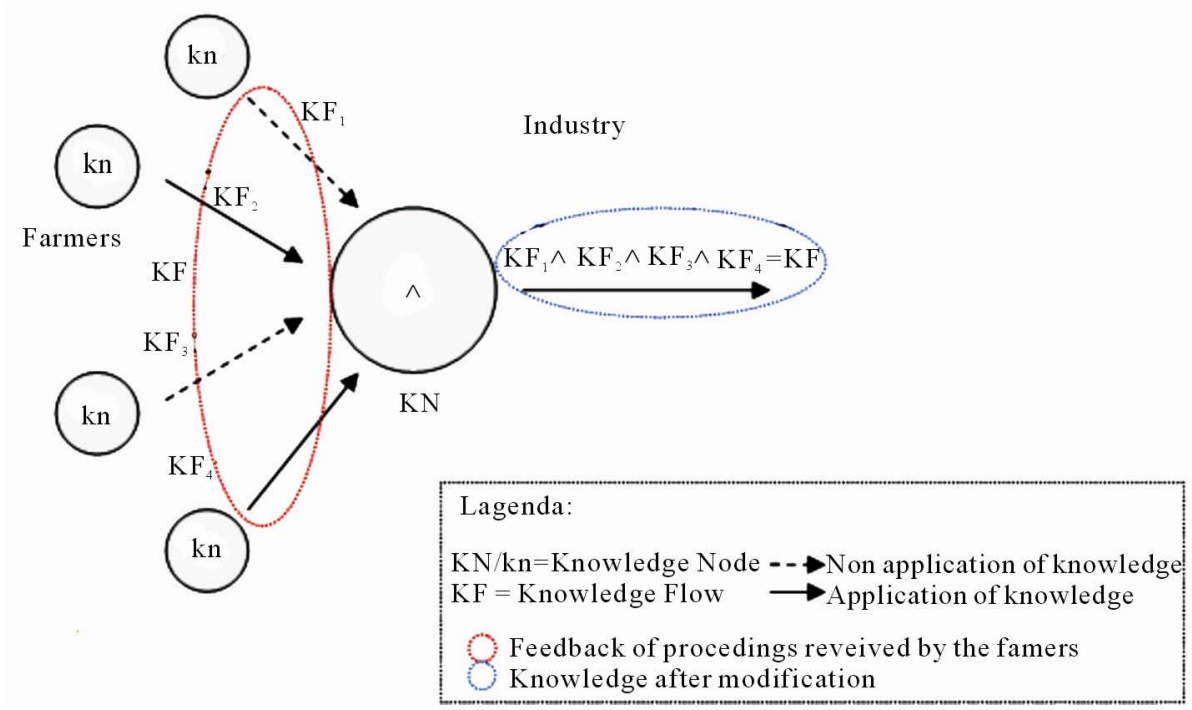

Figure 6. Junction connection of knowledge flows from farmers to industries.

the chain must be reached by the industries.

\section{Conclusions}

The identification and mapping of knowledge flows can help in understanding how the knowledge created in a given context (for example, between organizations in a supply chain) are modified after a process of sharing.

The importance of understanding the dynamics of knowledge flows within organizations is unquestionable. In the same way, it is believed that this understanding can be extended to inter-firm relationships and the production chain as a whole, once the Knowledge flows can help to coordinate the flow of work between organizations (near and/or geographically dispersed) and the way that these organizations work together, identifying the relevant skills and whom (which organization) has such knowledge.

Studies on knowledge flows can contribute to understand the processes of knowledge management (knowledge creation, dissemination, sharing and use) and the implementation of these processes within and between organizations.

In the context of relations between organizations in the supply chain studied (integrated farmers and industry) these areas are not different. It is crucial to promote explicit knowledge diffusion quickly, and reduce costs associated with identifying, locating and accessing knowledge that is distributed among the organizations that sometimes are unavailable or geographically distant.

After identifying a research gap, this article discussed the identification and mapping of knowledge flows between two types of organizations (inter firms level of analysis), agribusiness (industries) and producers (pig farmers). Some factors associated with environmental sustainability in the chain and market barriers have been highlighted as a practical context where it is necessary to consider the dynamics of knowledge flows.

On the practical side, this work contributes to the perception of the importance to identify and map knowledge flows. On the other hand, this article contributes to the achievement of future empirical research to examine knowledge flows among organizations of other supply chains, and suggests further studies to analyze any network structure (looking at the whole network) using the mapping proposed in this paper.

From the understanding of knowledge flows, further research aiming determine, predict and explore attitudes of the group, as well as their needs and priorities for each practice can be applied. Through the validation is also possible to weight the distribution of each practice and its quantification/measurement by level of importance. Studies can be performed to evaluate the effectiveness of these practices in different segments of the chain, as well as in similar chains.

\section{Acknowledgements}

The authors gratefully acknowledge the financial support of Coordenação de Aperfeiçoamento de Pessoal de Nível Superior CAPES [Federal Agency for Training and Development of Higher Education Academic Staff].

\section{REFERENCES}

[1] C. Spender and R. M. Grant, "Knowledge and the Firm: Overview,” Strategic Management Journal, Vol. 17, 1996, pp. 5-9.

[2] I. Nonaka, G. Von Krogh and S. Voelpel, “Organizational Knowledge Creation Theory: Evolutionary Paths and Future Advances,” Organization Studies, Vol. 27, No. 8, 
2006, pp. 1179-1208. doi:10.1177/0170840606066312

[3] H. Zhuge, “A Knowledge Flow Model for Peer-to-Peer Team Knowledge Sharing and Management," Expert Systems with Applications, Vol. 23, No. 1, 2002, pp. 23-30. doi:10.1016/S0957-4174(02)00024-6

[4] J. Singh, "Collaborative Networks as Determinants of Knowledge Diffusion Patterns," Management Science, Vol. 51, No. 5, 2005, pp. 756-770. doi:10.1287/mnsc.1040.0349

[5] N. J. Foss and T. Pedersen, “Transferring Knowledge in MNCs: The Role of Sources of Subsidiary Knowledge and Organizational Context," Journal of International Management, Vol. 8, No. 1, 2002, pp. 49-67. doi:10.1016/S1075-4253(01)00054-0

[6] O. Sorenson, J. Rivkin and L. Fleming, "Complexity, Networks and Knowledge Flow,” Research Policy, Vol. 35, No. 7, 2006, pp. 994-1017. doi:10.1016/j.respol.2006.05.002

[7] J. Mu, J. F. Tang and D. L. Maclachlan, “Absorptive and Disseminative Capacity: Knowledge Transfer in IntraOrganization Networks," Expert Systems with Applications, Vol. 37, No. 1, 2010, pp. 31-38. doi:10.1016/j.eswa.2009.05.019

[8] A. B. Jaffe, M. Trajtenberg and R. Henderson, "Geographic Localization of Knowledge Spillovers as Evidenced by Patent Citations," The Quarterly Journal of Economics, Vol. 108, No. 3, 2003, pp. 578-598. doi:10.2307/2118401

[9] B. Kogut and U. Zander, "Knowledge of the firm, Combinative Capabilities, and the Replication of Technology," Organization Science, Vol. 3, No. 3, 1992, pp. 383-397. doi:10.1287/orsc.3.3.383

[10] C. Lin, J.-C. Wu and D. C. Yen, "Exploring Barriers to Knowledge Flow at Different Knowledge Management Maturity Stages,” Information \& Management, Vol. 49, 2012, pp. 10-23. doi:10.1016/j.im.2011.11.001

[11] K. Yoo, E. Suh and K.-Y. Kim, "Knowledge Flow-Based Business Process Redesign: Applying a Knowledge Map to Redesign a Business Process,” Journal of Knowledge Management, Vol. 11, No. 3, 2007, pp. 104-125. doi:10.1108/13673270710752144

[12] J. F. Burnham, "Scopus Database: A Review," Biomedical Digital Libraries, Vol. 3, No. 1, 2006. doi:10.1186/1742-5581-3-1

[13] C. L. Weydmann, "Externalidades e Mudanças da Regulamentação Ambiental Para a Suinocultura Norte-Americana: É Possível No Caso Brasileiro?” Revista de Economia e Sociologia Rural, Vol. 43, No. 2, 2005, pp. 287305. doi:10.1590/S0103-20032005000200005

[14] M. Miele and P. Waquil, "Estrutura e Dinâmica dos Contratos Na Suinocultura de Santa Catarina: Um Estudo de Casos Múltiplos,” Estudos Econômicos, Instituto de Pesquisas Econômicas, Vol. 37, No. 4, 2007, pp. 817847.

[15] O. Sorenson, J. Rivkin and L. Fleming, "Complexity, Networks and Knowledge Flow," Research Policy, Vol. 35, No. 7, 2006, pp. 994-1017. doi:10.1016/j.respol.2006.05.002

[16] J. L. S. Santos, M. Uriona-Maldonado and R. N. Macedo dos Santos, "Inovação e Conhecimento Organizacional: um Mapeamento Bibliométrico das Publicações Científicas até 2009,” Organizações em Contexto, Vol. 7, No. 13, 2011, pp. 31-58.

https://www.metodista.br/revistas/revistas-metodista/inde x.php/OC/article/view/2712

[17] A. K. Gupta and V. Govindarajan, "Knowledge Flows within Multinational Corporations," Strategic Management Journal, Vol. 21, No. 4, 2000, pp. 473-496. doi:10.1002/(SICI)1097-0266(200004)21:4<473::AID-S MJ84>3.0.CO;2-I

[18] I. Björkman, W. Barner-Rasmussen and L. Li, "Managing Knowledge Transfer in MNCs: The Impact of Headquarters Control Mechanisms," Journal of International Business Studies, Vol. 35, No. 5, 2004, pp. 443-455. doi:10.1057/palgrave.jibs.8400094

[19] R. Mudambi and P. Navarra, "Is Knowledge Power? Knowledge Flows, Subsidiary Power and Rent-Seeking within MNCs,” Journal of International Business Studies, Vol. 35, No. 5, 2004, pp. 385-406. doi:10.1057/palgrave.jibs.8400093

[20] D. M. Decarolis and D. L. Deeds, “The Impact of Stocks and Flows of Organizational Knowledge on Firm Performance: An Empirical Investigation of the Biotechnology Industry,” Strategic Management Journal, Vol. 20, No. 10, 1999, pp. 953-968. doi:10.1002/(SICI)1097-0266(199910)20:10<953::AID-S MJ59>3.0.CO;2-3

[21] M. Schulz, “The Uncertain Relevance of Newness: Organizational Learning and Knowledge Flows,” Academy of Management Journal, Vol. 44, No. 4, 2001, pp. 661681. doi:10.2307/3069409

[22] J. H. Dyer and K. Nobeoka, "Creating and Managing a High-Performance Knowledge-Sharing Network: The Toyota Case," Strategic Management Journal, Vol. 21, No. 3, 2000, pp. 345-367. doi:10.1002/(SICI)1097-0266(200003)21:3<345::AID-S MJ96>3.0.CO;2-N

[23] A. R. Montazemi, J. J. Pittaway, H. Q. Saremi and Y. Wei, "Factors of Stickiness in Transfers of Know-How between MNC Units,” Journal of Strategic Information Systems, Vol. 21, No. 1, 2012, pp. 31-57. doi:10.1016/j.jsis.2012.01.001

[24] M. R. Tagliaventi, F. Bertolotti and D. M. Macrì, “A Perspective on Practice in Interunit Knowledge Sharing," European Management Journal, Vol. 28, No. 5, 2010, pp. 331-345. doi:10.1016/j.emj.2010.04.001

[25] M. Miele and P. Waquil, "Cadeia Produtiva da Carne Suína No Brasil,” Revista de Política Agrícola, Vol. 16, No. 1, 2007, pp. 75-87.

[26] M. R. Roesler and E. A. Cesconeto, “A Produção de Suínos e as Propostas de Gestão de Ativos Ambientais: O Caso da Região de Toledo-Paraná," Informe GEPEC, Vol. 7, No. 2, 2003, pp. 1-19.

[27] M. Miele, "Contratos, Especialização, Escala de Produção e Potencial Poluidor Na Suinocultura de Santa Catarina,” 8 September 2006.

http://www.lume.ufrgs.br/bitstream/handle/10183/7244/0 00541233.pdf?sequence $=1$ 
[28] A. G. Silva Jr., R. Helbig and G. Schiefer, "Sistema Informatizado de Gestão da Qualidade: Uma Aplicação
Para a Suinocultura na Alemanha,” Belo Horizonte, 1997, pp. 527-533. http://www.jstor.org/stable/3875201 